\title{
Ovarian hormones do not affect the initiation and maintenance of intravenous self-administration of heroin in the female rat
}

\author{
JANE STEWART, BARBARA WOODSIDE, and YAVIN SHAHAM \\ Concordia University, Montreal, Quebec, Canada
}

\begin{abstract}
The effect of ovarian hormones on the initiation and maintenance of heroin intravenous selfadministration was studied in ovariectomized female rats. In Experiment 1 (initiation), the behavior of groups of females $(n=8)$ ovariectomized (OVX), injected with $10 \mu \mathrm{g}$ estradiol benzoate (EB) every 3 days (OVX $+\mathrm{EB})$, and intact, was compared with that of intact males $(n=7)$ exposed to an ascending series of doses of heroin $(6.125-50 \mu \mathrm{g} / \mathrm{kg}$ per infusion) on a fixed ratio-FR-1-reinforcement schedule. Twelve 3 -h sessions per dose were given, 2 per day in the dark and 2 in the light period of a 12:12-h light:dark cycle. No differences in rate of responding between groups were observed at any of the heroin doses during acquisition or during tests given after acquisition on a descending series of doses. In Experiment 2 (maintenance), $7 \mathrm{OVX}$ female rats were trained to self-administer heroin on an FR-1 reinforcement schedule. They were then switched to a progressive ratio schedule, 4 sessions per day, $4 \mathrm{~h}$ each, and a regimen of $\mathrm{EB}$ and progesterone $(\mathrm{P})$ injections was initiated during which all animals were tested over a 5-day period (cycle) at each of four doses of heroin (50, 25, 12.5 , and $0.0 \mu \mathrm{g} / \mathrm{kg}$ per infusion). Neither EB, given on Day 3, nor P, given on Day 5 of each cycle, affected the highest ratio achieved (breakpoint) or number of heroin infusions taken. These results suggest that the sensitivity of female and male rats to the reinforcing effects of heroin is not different, and that, in females, the reinforcing effects are not affected by circulating ovarian hormones.
\end{abstract}

Sex differences in the magnitude of responses to stimulant and opioid drugs have been the object of numerous studies in recent years. It has been shown, for example, that female rats are more responsive than males to the behavioral activating effects of amphetamine and that circulating ovarian hormones are largely responsible for these differences (Becker, 1990; Becker \& Beer, 1986; Castner, Xiao, \& Becker, 1993; Forgie \& Stewart, 1993, 1994a, 1994b). These results are consistent with those showing that estrogens facilitate striatal dopamine release directly (Castner et al., 1993) and can modulate the effects of stimulant drugs in the striatum (Becker, 1990; Becker \& Beer, 1986). In an attempt to assess whether such differences in response to stimulant drugs would be reflected in their reinforcing properties, Roberts, Bennett, and Vickers (1989) studied the self-administration of cocaine throughout the estrous cycle using a PR (progressive ratio) schedule of reinforcement. Under this schedule, the number of responses required to obtain a drug infusion increases from infusion to infusion until the an-

This research was funded by grants to J.S. from the Medical Research Council of Canada and from the Fonds pour la Formation de Chercheurs et l'Aide à la Recherche (FCAR, Québec). Y.S. was supported by a postdoctoral fellowship award from the Medical Research Council of Canada. Thanks are extended to Demetra Rodaros for her expert technical assistance. Correspondence should be directed to J. Stewart, Department of Psychology, Concordia University, 1455 de Maisonneuve Blvd. W., Montreal, Quebec, Canada H3G 1M8 (e-mail: stewart@csbn1.concordia.ca). imal ceases leverpressing and the highest ratio completed is referred to as the breakpoint. They found that female rats achieved higher breakpoints during estrus than during other stages of the cycle and that estrous females had higher breakpoints than males; no differences between conditions were found when animals were reinforced for every leverpress, an FR-1 (fixed ratio) schedule.

In contrast to what is known about sex differences in response to the behavioral activating and reinforcing properties of amphetamine and cocaine, little is known about sex differences with respect to these effects of opioid drugs. There are several reports indicating that female rats self-administer morphine as well as ethanol and cocaine more readily than males when the drugs are presented orally (e.g., Hadaway, Alexander, Coambs, \& Beyerstein, 1979; Hill, 1978; Taylor, Harris, \& Vogel, 1990). The results of such studies, however, are difficult to interpret for two reasons. First, there was no attempt made in these studies to assess the role of taste factors per se in the sex differences observed. This would be particularly important in studies employing oral presentation of bitter solutions, because it has been shown that female rats are less likely to reject bitter quinine solutions than are male rats (Ganchrow, Lieblich, \& Cohen, 1981). Second, no attempt was made in these studies to establish that the drug served as a reinforcer (for example, that preference for the drug exceeded preference for water).

In the present studies, we chose to assess the effects of sex and of ovarian hormones on the intravenous selfadministration of heroin, using methods considered to be 
particularly sensitive to individual differences in the reinforcing properties of drugs. In the first experiment, we studied the effects of sex, ovariectomy, and estrogen replacement on the initiation of self-administration of heroin in drug-naive animals going from barely detectable doses to ones that are normally self-administered by rats (Deminiere, Piazza, Le Moal, \& Simon, 1989). In the second experiment, we studied the effects of changes in level of estradiol and progesterone in a group of female rats using a PR schedule of reinforcement thought to assess directly the reinforcing effects of drugs (Roberts et al., 1989)

\section{EXPERIMENT 1 Initiation of Self-Administration}

\section{Method}

Subjects. Twenty-four female Wistar rats (Charles River, Canada), weighing 250-350 g, and 7 males, weighing $300-400 \mathrm{~g}$, both at the start of the experiment, were the subjects. Following surgical implantation of intravenous (i.v.) catheters, the animals were housed in the operant chambers and allowed at least 1 week to recover. Food (standard rodent chow) and water were available continuously in the operant chambers and the light-dark cycle was reversed (lights on $2130-0930 \mathrm{~h}$ ).

Surgery. The rats were anesthetized with sodium pentobarbital (40-45 mg/kg for females and $65 \mathrm{mg} / \mathrm{kg}$ for males, i.p.) and were given atropine-sulfate $(0.6 \mathrm{mg} / \mathrm{ml} ; 0.3 \mathrm{ml} /$ animal $)$ and Ayercillin (300,000 IU; $0.2 \mathrm{ml} / \mathrm{animal})$ prior to surgery. Silastic catheters (Dow Corning, 0.02-in. i.d., 0.037-in. o.d.) were implanted into the right jugular vein. The catheters were secured to the vein with a silk suture and passed subcutaneously to the top of the skull where they exited into a connector (a modified 22-ga cannula) mounted to the skull with dental cement. The animals were ovariectomized by bilateral dorsal incisions immediately following the implantation of the catheters. Catheter patency was maintained by injecting $0.1-0.2 \mathrm{ml}$ of a saline-heparin solution $(30 \mathrm{U}$ heparin $/ \mathrm{ml}$ ) into the catheter each morning; streptokinase $(1,000 \mathrm{U} / \mathrm{ml}$, Sigma) was added to the saline-heparin solution every other day.

Apparatus. The experiment was conducted in operant conditioning chambers in which the animals lived. Each operant box had two levers raised to a height of $9 \mathrm{~cm}$ above the floor. Pressing on one lever (the "active" retractable lever) activated the infusion pump. Leverpressing on the other lever (the "inactive" stationary lever) was recorded, but did not activate the infusion pump. A given dose of heroin was administered at a volume of $0.13 \mathrm{ml}$ during a 20 -sec period. During this time period, a bulb located above the active lever was lit for $20 \mathrm{sec}$. Barpresses during those $20 \mathrm{sec}$ were counted, but did not lead to further infusions.

Drugs. Heroin (diacetylmorphine $\mathrm{HCl}$, Health and Welfare, Canada) was dissolved in physiological saline for the i.v. injections. The replacement hormones used were estradiol benzoate (EB) and progesterone (P) (Sigma, St. Louis); they were injected in a volume of $0.1 \mathrm{ml}$ of peanut oil, subcutaneously (s.c.). The doses of EB and $P$ used were $10 \mu \mathrm{g}$ and $0.5 \mathrm{mg}$ per injection, respectively, doses sufficient to reinstate sexual receptivity (Pfaus \& Pfaff, 1992). EB alone or EB and P were injected according to the schedules described below for each experiment.

Experimental groups. Four groups of animals were studied in Experiment 1. Two of these were ovariectomized females (OVX, $n=8$ ) and ovariectomized, estradiol benzoate treated females (OVX-EB, $n=8$ ). Given that estrogen levels drop to negligible levels within 3 days of ovariectomy (Goodman, 1978), the replacement regimen was begun immediately after surgery to prevent the loss of estrogen's effectiveness that can occur following a major reduction in estrogen level. Animals in the OVX-EB group were given EB ( $10 \mu \mathrm{g}$ per injection) every third day $30 \mathrm{~min}$ prior to lights out for the duration of the study. This replacement regimen is similar to that used by Forgie and Stewart (1993) and has been found to potentiate the locomotor stimulating effects of amphetamine in ovariectomized animals. The other two groups were intact females $(n=8)$ and intact males $(n=7)$.

Procedure. The animals self-administered heroin i.v. for four sessions per day (two during the dark period and two during light period) for 7 days a week under a continuous (FR-1) schedule of reinforcement. The drug sessions were during the hours of $1000-1300,1600-1900,2200-0100$, and 0400-0700. Throughout each drug session, the red houselight was turned on and the active lever was extended into the operant chamber. At the beginning of each session, the white light above the active lever was turned on for $30 \mathrm{sec}$. The animals self-administered heroin at each of four doses $(6.125,12.5,25$, and $50 \mu \mathrm{g} / \mathrm{kg}$ per infusion) given in an ascending order. Each of the four doses was available for 3 days ( 4 sessions per day). Following this 12-day initiation phase, the dose of heroin was reduced daily over the following 4 days from 50 , to 25 , to $12.5 \mu \mathrm{g} / \mathrm{kg}$ per infusion and then to 0 (saline condition). The dose-reduction sessions were conducted to determine whether any group differences might exist in the dose-response curve following the initiation of heroin self-administration behavior.

Statistical analyses. Data from each of the two sessions in the dark and light periods were averaged within each day. Analyses were done separately for the light and dark periods. Data from the initiation phase were analyzed using repeated measures analysis of variance (ANOVA), with day (Days 1, 2, and 3 at each drug dose) and dose $(6.125,12.5,25$, and $50 \mu \mathrm{g} / \mathrm{kg} /$ infusion $)$ as the within-subjects factors and group (OVX, OVX-EB, female, male) as the between-subjects factor. The data for the dose-reduction curve following the initiation phase was analyzed by a repeated measures ANOVA, with dose as the within-subjects and group as the between-subjects factors.

\section{Results}

Three animals ( 2 from the OVX-EB group and 1 from the male group) did not complete the experiment due to catheter failure after the initial assessment of the 25 $\mu \mathrm{g} / \mathrm{kg}$ per infusion dose. Response rate on the inactive lever was very low throughout the experiment (data not shown). This was probably due to the fact that the animals had lived in the operant conditioning chambers for 1 week prior to the start of the experiment, allowing for extinction of pressing on this lever.

Figure 1 shows the mean number of infusions of heroin at each of the four doses examined during the initiation phase. The ANOVA revealed significant main effects for dose [dark, $F(3,72)=13.2, p<.001$; light, $F(3,72)=15.9, p<.001]$ and day $[$ dark, $F(2,48)=12.3$, $p<.001$; light, $F(2,48)=15.9, p<.001]$. These effects result from the progressive increase in the number of infusions taken from heroin dose 6.125 to dose $25 \mu \mathrm{g} / \mathrm{kg}$ per infusion, and from the overall tendency to increase the number of infusions over days at the 12.5-, 25-, and $50-\mu \mathrm{g} / \mathrm{kg}$ doses of heroin (data in Figure 1 are collapsed across days for each dose). By contrast, no significant group effect or group $\times$ dose and group $\times$ day interactions were found. Additional analyses carried out for each drug dose and each day separately failed to reveal any group differences. 

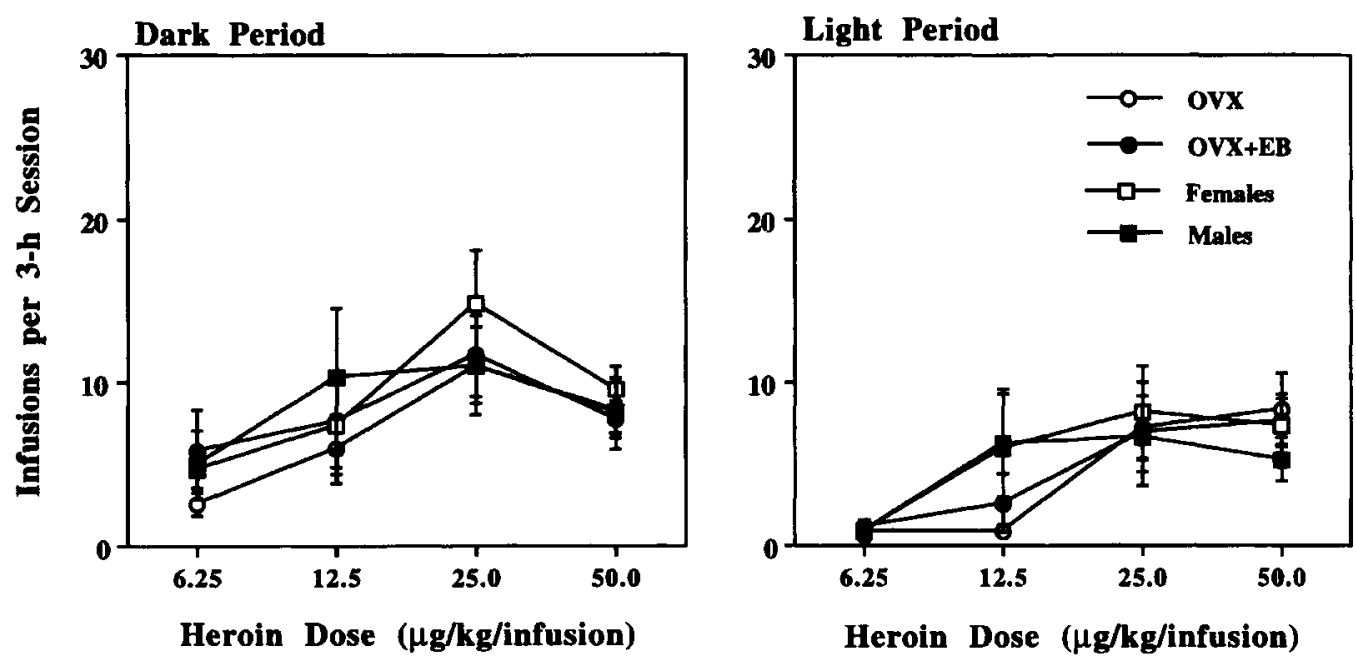

Figure 1. Dose-response during dose-reduction phase following initiation of self-administration: Mean $( \pm S E M)$ number of infusions of heroin at each of the four doses presented to the animals in ascending order. Data are shown separately for the dark and light periods of the cycle and are the means for the last day at each dose. OVX = ovariectomized, EB = estradiol benzoate.

The data were further analyzed by the nonparametric median test because the distributions of the responses were skewed to the right in each of the experimental groups. The nonparametric analyses also failed to reveal any group differences at any of the doses used. In general, regardless of the group condition, most animals engaged in stable leverpressing for heroin within each hour of the sessions at the two highest heroin doses ( 25 or $50 \mu \mathrm{g} / \mathrm{kg}$ per infusion). However, 1 male and 2 intact females never engaged in stable leverpressing during this phase and could not be said to have initiated drug self-administration behavior.

Figure 2 shows the mean number of infusions during the dose-reduction phase following initiation. The data from

Dark Period

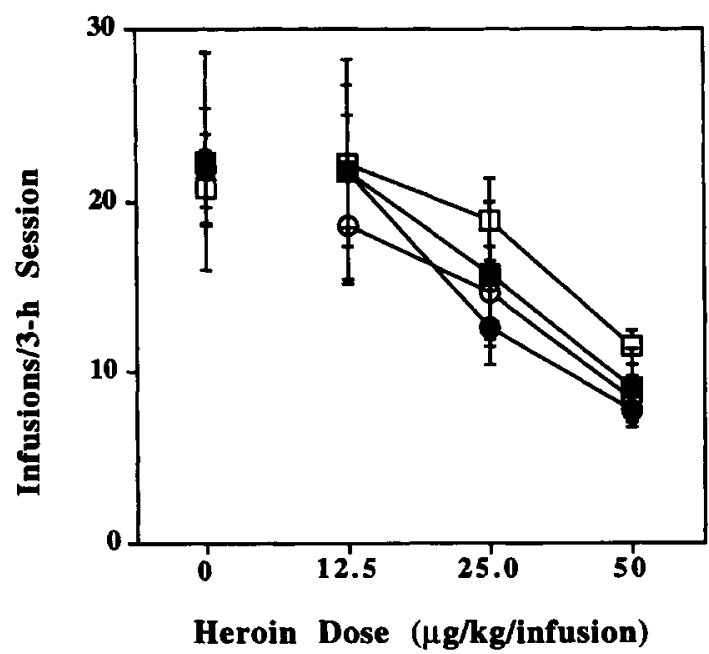

the 3 animals mentioned above were not included. As expected, there was an increase in response rate as the dose was decreased, and the ANOVAs revealed a main effect of dose during the dark $[F(3,63)=36.1, p<.001]$ and light periods $[F(3,63)=14.2, p<.001]$. No group differences were observed at any of the doses tested.

\section{EXPERIMENT 2 \\ Maintenance of Self-Administration}

To determine the effects of ovarian steroids on the maintenance of heroin self-administration, ovariectomized animals were first trained to self-administer heroin on a

Figure 2. Dose-response after acquisition: Mean ( $\pm S E M$ ) number of infusions of heroin at each of the four doses presented to the animals in descending order after acquisition of self-administration. Data are shown separately for the dark and light periods of the cycle and are the means for the 1 day at that dose. OVX $=$ ovariectomized, $\mathrm{EB}=$ estradiol benzoate.

\section{Light Period}

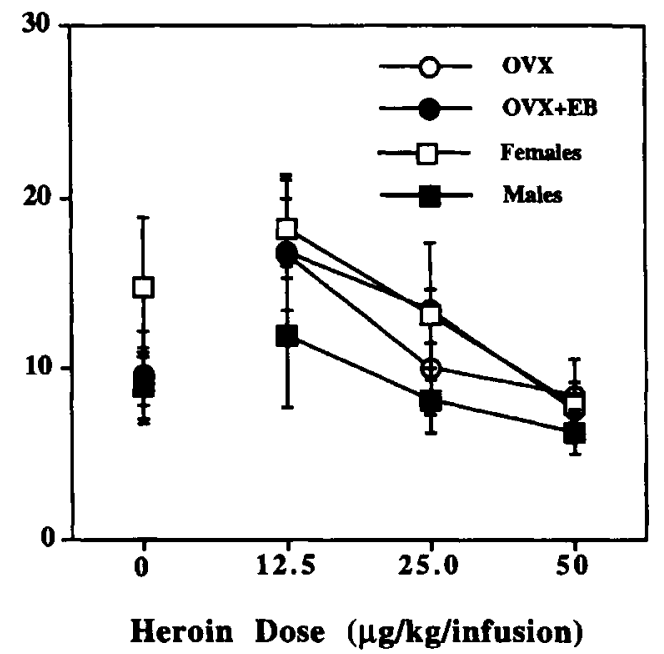


$\mathrm{PR}$ ratio schedule and were then tested under a hormone replacement regimen designed to resemble the timing of hormone changes across the estrous cycle (Berglund, Derendorf, \& Simpkins, 1988).

\section{Method}

Subjects. Seven female Wistar rats (Charles River, Canada), weighing $250-350 \mathrm{~g}$ at the start of the experiment, served as subjects. Following implantation of the intravenous (i.v.) catheters and ovariectomy, the animals were housed in the operant chambers and given at least 1 week to recover. The initial training on the FR-l schedule was carried out in the absence of hormone treatments. The first injections of EB were given approximately 2 weeks after ovariectomy.

Procedure. The animals were allowed to self-administer heroin intravenously during four sessions per day ( 2 in the dark period and 2 in the light), 7 days a week. The drug sessions were between the hours of $1000-1400,1600-2000,2200-0200$, and $0400-0800$. The turning on of lights and the introduction of the levers was the same as in Experiment 1. The animals were initially trained to self-administer heroin at a dose of $50 \mu \mathrm{g} / \mathrm{kg}$ per infusion on an FR-1 schedule. Subsequently, a PR schedule, adapted from Roberts and Bennett (1993), was implemented. Each session began with a response requirement of 2 . With each successive reinforcement, the response requirement was escalated through the steps: $4,6,9$, $12,16,20,25,32,40,50,62,77$, etc.

The PR sessions were in place until performance stabilized, for a mean of 2.1 days. Subsequently, the animals received the first EB injection. They then self-administered heroin on the PR schedule for a further 6 or 9 days, during which EB was administered on two or three occasions, every third day to maintain sensitivity to estrogen and progesterone. Following this period, the animals self-administered heroin for four more 5-day cycles, each at one of four descending doses of heroin $(50,25,12.5$, and $0 \mu \mathrm{g} / \mathrm{kg}$ per infusion). Within each 5 -day cycle, all animals were injected with EB on Day 13 and with P on Day 5. No injections were given on Days 1, 2, and 4 of each 5-day cycle.

Statistical analyses. The data from the heroin sessions (12.5, 25 , and $50 \mu \mathrm{g} / \mathrm{kg}$ per infusion) were analyzed separately from those of saline, because the saline condition constituted an extinction condition. Because each session of each day occurred at different intervals after the steroid injections, separate analyses (one for each of the four sessions) were used to compare the effects of heroin dose and cycle day. For the analyses of behavior when the animals were self-administering heroin, the within-subject factors were the heroin dose $(50,25$, and $12.5 \mu \mathrm{g} / \mathrm{kg}$ per infusion) and cycle day (i.e., Day 1, Day 2, estradiol day (3), Day 4, and progesterone day (5)). For the data obtained when the animals selfadministered saline, the within-subject factor was the cycle day.
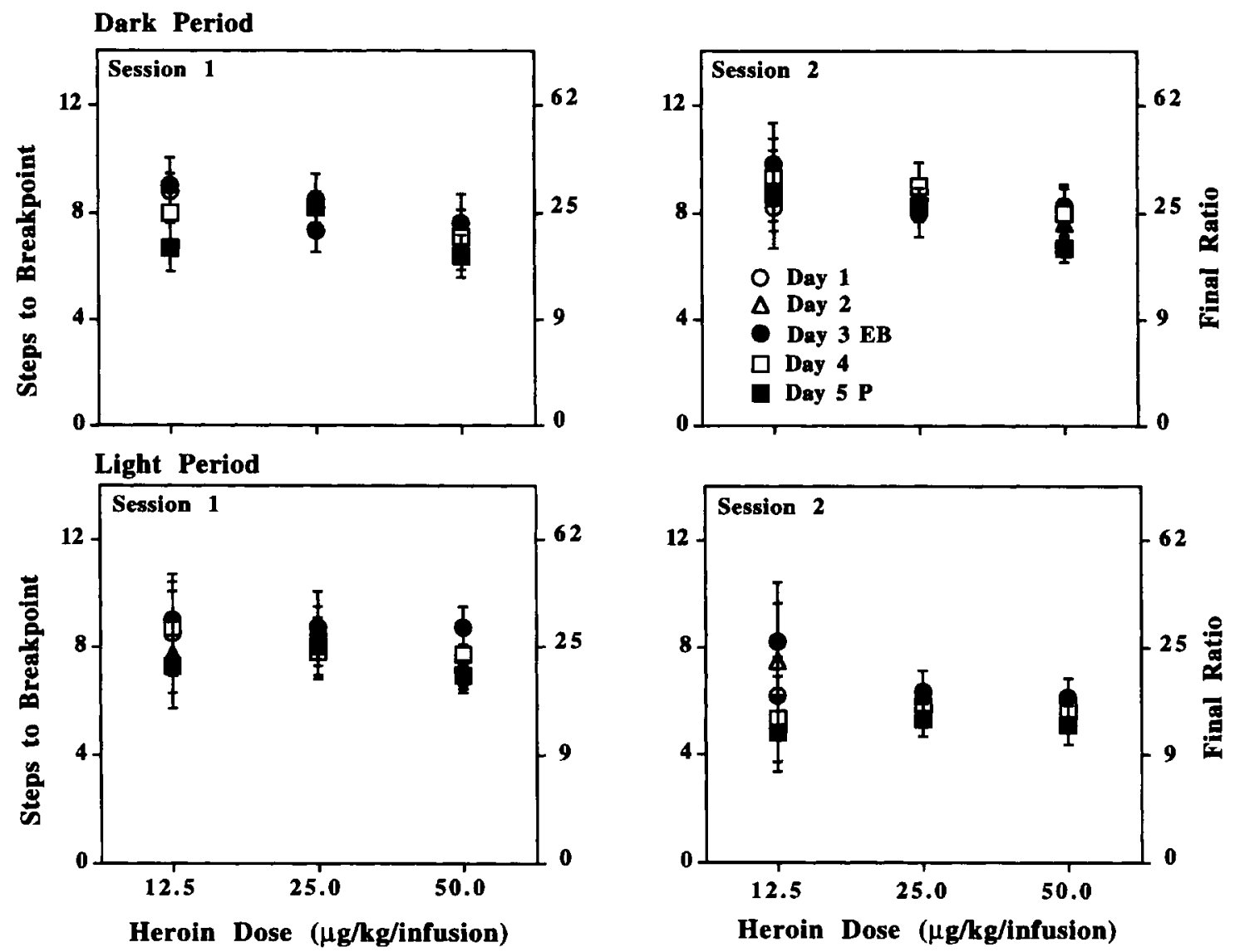

Figure 3. Progressive ratio performance: Mean ( $\pm S E M$ ) number of steps to breakpoint (left axis) and final ratio achieved (right axis) by females during the 5 treatment days of each cycle. The five symbols shown for each dose represent the 5 days of the cycle. The animals were trained and stabilized at $50 \mu \mathrm{g} / \mathrm{kg}$ per infusion and were then presented with each dose of heroin for 5 days, the period of one cycle. $\mathbf{E B}=$ estradiol benzoate, $P=$ progesterone. 


\section{Results}

It took the animals a mean of 4.7 days to achieve a stable leverpressing responding on the FR-1 schedule. The mean time to achieve stable responding on the PR schedule prior to the first injection of EB was 2.1 days. During the next 6-9 days on the PR schedule, when the EB injections were initiated, the rate of responding on the $50-\mu \mathrm{g} /$ $\mathrm{kg}$-per-infusion dose was stable.

Figure 3 presents mean number of steps to breakpoint (the final ratio achieved) during the sessions in the dark and light periods across the four cycles at each of the doses presented. No significant effects of heroin dose or cycle day were observed during either of the sessions in the dark period or in the first session of the light period for response rates obtained in the three drug conditions $(12.5,25$, and $50 \mu \mathrm{g} / \mathrm{kg}$ per infusion). In the second session of the light period, a significant effect of cycle day was found $[F(4,20)=5.1, p<.01]$. The latter result, seen only during this last session in the light period, stems from the fact that the responding was somewhat lower on Day 5 of each cycle ( $P$ injection) than on the other days. Analyses within each dose, however, revealed only a marginally significant effect of cycle day at the 12.5$\mu \mathrm{g} / \mathrm{kg}$ per infusion dose $[F(4,20)=2.3, p=.09]$. Taken together, the performance of the animals was stable across the days of the cycle and across the three doses of heroin.

When the responses of the animals were reinforced with saline, a significant effect of cycle day was observed in all four sessions $(p<.05)$. This effect stems from the fact that leverpressing decreased over days due to the extinction conditions.

\section{GENERAL DISCUSSION}

In the two experiments reported here, we found no evidence that sex or ovarian hormones affected the reinforcing properties of heroin administered intravenously. In Experiment 1, no differences between treatment groups in the readiness to initiate self-administration of low doses of heroin (starting at $6.125 \mu \mathrm{g} / \mathrm{kg}$ per injection) were found. Neither did the groups differ in their propensity to take heroin as the dose increased; all groups were equally sensitive to the dose changes. In Experiment 2, no effects of EB or $P$ were found over the days of the cycle on the PR schedule at any of the doses presented. These findings differ from those reported previously for the stimulant drug cocaine in studies using the PR schedule (Roberts et al., 1989) and probably reflect differences in the mechanism of action of these two drugs on the neural substrates underlying their reinforcing effects. For example, although both stimulant and opioid drugs interact with neural elements in the ventral tegmental area (VTA) and nucleus accumbens septi (NAS), considered to underlie their reinforcing properties, they do so by different mechanisms. Opioids act to increase firing rates of mesolimbic dopamine (DA) neurons through their actions at opioid receptors in the VTA, where they act to release DA cells from inhibition (see Di Chiara \& North,
1992). In addition, opioids have been shown to have behavioral activating and reinforcing effects via their direct actions on postsynaptic cells in the NAS (see Stinus, Cador, \& Le Moal, 1992), a terminal region of the DA neurons. Stimulant drugs increase extracellular DA in the NAS, in the case of amphetamine, by causing impulseindependent DA release and blockade of DA reuptake, and in the case of cocaine, by reuptake blockade. As mentioned earlier, estrogens have been shown both to facilitate amphetamine-induced DA release in striatum and NAS (Becker, 1990) and to enhance the effects of DA agonists on postsynaptic striatal cells (Mermelstein, Becker, \& Surmeier, 1993). The possible interactions between the effects of opioid drugs and estrogens in the striatum have not, to our knowledge, been explored.

It can be mentioned that the PR schedule as instituted here was relatively insensitive to doses of heroin between 12.5 and $50 \mu \mathrm{g} / \mathrm{kg}$ per infusion. In the present experiment, animals started each session at the lowest ratio and thus would have taken a considerable amount of drug by the time the higher ratios were reached. In a study by Roberts and Bennett (1993), exposure to daily heroin was minimized by setting the initial response requirements two steps below the final ratio achieved on the previous day. Even so, the animals were not very sensitive to changes in dose. Over a range of doses between 12.5 and $100 \mu \mathrm{g}$ per injection (approximately $37.5-300 \mu \mathrm{g} / \mathrm{kg}$ per injection), the only significant effect of dose was seen between 12.5 and $50 \mu \mathrm{g} /$ injection. In spite of this insensitivity to dose, self-administration of heroin on a PR schedule does seem to be sensitive to pharmacological and environmental manipulations. Roberts and Bennett (1993) showed that the injection of the opioid antagonist naltrexone decreased the final ratio achieved at the 12.5$\mu \mathrm{g} /$ injection dose, and we have shown that the final ratio achieved for doses of 25 and $50 \mu \mathrm{g} / \mathrm{kg}$ per injection can be altered by exposure to footshock stress (Shaham \& Stewart, 1994).

Finally, the lack of effect of both gender and ovarian hormones on the reinforcing effects of opioids shown here contrasts with the well-described effects of these factors on the analgesic and other depressant actions of opioids. For example, male rats are more sensitive to the analgesic properties of intracerebroventricularly administered morphine than are females (Kepler, Kest, Kiefel, Cooper, \& Bodnar, 1989). Moreover, the analgesic, sedative, and hypothermic responses of female rats to morphine administered systemically are modulated by the stage of the estrous cycle and, unlike what we originally predicted for the reinforcing effects of opioids, their analgesic potency is decreased by estrogens and progesterone (Berglund et al., 1988; Berglund \& Simpkins, 1988). More recently, it has been shown that estrogens suppress $\mu$-opioid hyperpolarization of neurons in the arcuate nucleus of the hypothalamus (Kelly, Loose, \& Ronnekleiv, 1992). Furthermore, estrous-cycle variation in responsiveness to morphine is accompanied by changes in density of naloxone binding sites in a number of hypothalamic areas as well as the cerebral cortex (Weiland 
$\&$ Wise, 1990). There are no data, however, concerning estrogen-opioid receptor interactions in those areas of the brain assumed to underlie the reinforcing properties of opioid drugs. The data presented in the present paper suggest that if there are such changes, they are not sufficient to affect opioid self-administration behavior.

\section{REFERENCES}

BECKER, J. B. (1990). Estrogen rapidly potentiates amphetamine induced striatal dopamine release and rotational behavior during microdialysis. Neuroscience Letters, 118, 169-171.

BECKER, J. B., \& BEER, M. E. (1986). The influence of estrogen on nigrostriatal dopamine activity: Behavioral and neurochemical evidence for both pre- and postsynaptic components. Behavioural Brain Research, 19, 27-33.

Berglund, L. A., Derendorf, H., \& Simpkins, J. W. (1988). Desensitization of brain opiate receptor mechanisms by gonadal steroid treatments that stimulate luteinizing hormone secretion. Endocrinology, 122, 2718-2725.

Berglund, L. A., \& SimpKins, J. W. (1988). Alterations in brain opiate receptor mechanisms on proestrous afternoon. Neuroendocrinology, 48, 394-400.

Castner, S. A., XiaO, L., \& Becker, J. B. (1993). Sex differences in striatal dopamine: In vivo microdialysis and behavioral studies. Brain Research, 610, 127-134.

Deminiere, J. M., Piazza, P. V., Le Moal, M., \& Simon, H. (1989). Experimental approach to individual vulnerability to psychostimulant addiction. Neuroscience \& Biobehavioral Reviews, 13, 141-147.

Di Chiara, G., \& NorTh, R. A. (1992). Neurobiology of opiate abuse. Trends in Pharmacological Science, 13, 185-193.

ForgiE, M. L., \& STEWART, J. (1993). Sex differences in amphetamineinduced locomotor activity in adult rats: Role of testosterone exposure in the neonatal period. Pharmacology, Biochemistry \& Behavior, 46, 637-645.

Forgie, M. L., \& StewarT, J. (1994a). Effect of prepubertal ovariectomy on amphetamine-induced locomotor activity in adult female rats. Hormones \& Behavior, 28, 241-260.

ForGiE, M. L., \& STEWART, J. (1994b). Sex differences in the locomotoractivating effects of amphetamine: Role of circulating testosterone in adulthood. Physiology \& Behavior, 55, 639-644.

Ganchrow, J. R., Lieblich, I., \& CohEN, E. (1981). Consummatory responses to taste stimuli in rats selected for high and low rates of self-stimulation. Physiology \& Behavior, 27, 971-976.

Goodman, R. L. (1978). A quantitative analysis of the physiological role of estradiol and progesterone in the control of tonic surge se- cretion of luteinizing hormone in the rat. Endocrinology, 102, 142 150.

Hadaway, P. F., Alexander, B. K., Coambs, R. B., \& Beyerstein, B. (1979). The effect of housing and gender on preference for morphinesucrose solutions in rats. Psychopharmacology, 66, 87-91.

HILL, S. Y. (1978). Addiction liability of tryon rats: Independent transmission of morphine and alcohol consumption. Pharmacology, Biochemistry \& Behavior, 9, 107-110.

Kelly, M. J., LoOSE, M. D., \& RonNeKLeiv, O. K. (1992). Estrogen suppresses $\mu$-opioid- and $\mathrm{GABA}_{\mathrm{B}}$-mediated hyperpolarization of hypothalamic arcuate neurons. Journal of Neuroscience, 12, 2745. 2750 .

KePler, K. L., Kest, B., Kiefel, J. M., CoOper, M. L., \& Bodnar, R. J. (1989). Roles of gender, gonadectomy and estrous phase in the analgesic effects of intracerebroventricular morphine in rats. Pharmacology, Physiology \& Behavior, 34, 119-127.

Mermelstein, P. G., Becker, J. B., \& Surmeier, D. J. (1993). 17bestradiol inhibits $\mathrm{w}$-conotoxin sensitive (N-type) calcium channels in rat striatal neurons. Society for Neuroscience Abstracts, 19, 1527.

Pfaus, J. G., \& PfafF, D. W. (1992). Mu, delta, and kappa opioid receptor agonists selectively modulate sexual behaviors in the female rat: Differential dependence on progesterone. Hormones \& Behavior, 26, 457-472.

Roberts, D. C. S., \& Bennett, S. A. L. (1993). Heroin selfadministration in rats under a progressive ratio schedule of reinforcement. Psychopharmacology, 111, 215-218.

Roberts, D. C. S., BENNETt, S. A. L., \& Vickers, G. J. (1989). The estrous cycle affects cocaine self-administration on a progressive ratio schedule in rats. Psychopharmacology, 98, 408-411.

ShaHAM, Y., \& STEWART, J. (1994). Exposure to mild stress enhances the reinforcing efficacy of intravenous heroin self-administration in rats. Psychopharmacology, 114, 523-527.

Stinus, L., CADOR, M., \& Le MoAL, M. (1992). Interaction between endogenous opioids and dopamine within the nucleus accumbens. In P. W. Kalivas \& H. H. Samson, The neurobiology of drug and alcohol addiction (Annals of the New York Academy of Sciences, Vol. 654, pp. 254-273). New York: New York Academy of Sciences.

TAYLOR, J., HARRIS, N., \& VOGEL, W. H. (1990). Voluntary alcohol and cocaine consumption in "low" and "high" stress plasma catecholamine responding rats. Pharmacology, Biochemistry \& Behavior, 37, 359-363.

WEILAND, N. G., \& WISE, P. M. (1990). Estrogen and progesterone regulate opiate receptor densities in multiple brain regions. Endocrinology, 126, 804-808.

(Manuscript received July 28, 1995; revision accepted for publication February 25, 1996.) 